\title{
TESTING OF A RASTER MAGNET SYSTEM FOR EXPANDING THE APT PROTON BEAM *
}

\author{
S. Chapelle, T. L. Smith, General Atomics, San Diego, CA \\ D. J. LeBon, M. E. Schulze ${ }^{\#}$, R. E. Shafer, General Atomics, Los Alamos, NM
}

\section{Abstract}

A method of expanding the $1700 \mathrm{MeV}, 100 \mathrm{~mA}$ proton beam of the APT linear accelerator onto the 19 by $190 \mathrm{~cm}$ target has been devised using eight ferrite dipole magnets. These magnets deflect the beam in the $\mathrm{x}$ and $\mathrm{y}$-plane, and thereby paint the target area uniformly with a rastered pattern. Insulated Gate Bipolar Transistor (IGBT)-based power modulators drive the raster magnets with triangular current waveforms that are synchronized using voltage controlled crystal oscillators and phase-locked loops (PLLs). Redundant fault detection circuits monitor both the ac magnet currents and magnetic fields to ensure proper operation. This paper presents the test results taken on an integrated prototype system including eight magnets, the associated modulators, the master clock and the fault detection circuitry.

\section{BACKGROUND}

A raster-type beam expander system, originally described in Ref. [1,2], has been built and the integrated system has been tested. The full prototype system allows evaluation of several aspects of the system-level operation which include interactions between the eight magnets and their power modulators and the ability of the fault detection circuitry to independently detect problems with the raster system. Fig. 1 shows the raster magnets as they fit into the high energy beam transport (HEBT) portion of the APT Linac.

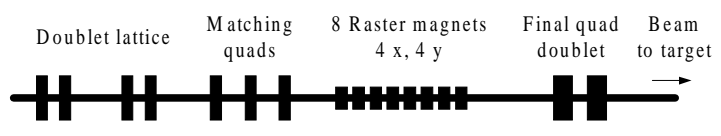

Figure 1: Raster magnets in HEBT

\section{SYSTEM DESCRIPTION}

The block diagram of the Raster Magnet System shown in Fig. 2 consists of the 1) IGBT modulator, 2) master clock, 3) raster magnet and 4) fault detection circuitry.

\subsection{IGBT Modulator}

The IGBT modulator consists of an ac/dc converter, a capacitor bank, and an IGBT H-bridge with a gate driver board. The modulator circuit is shown schematically in Fig. 3. Each modulator is powered by uninterruptible

*Work supported by DOE contract DE-AC04-96AL89607

"e-mail: martin.schulze@gat.com

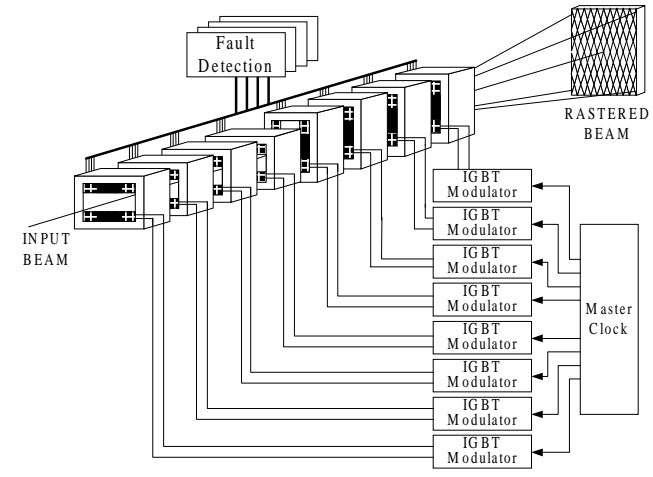

Figure 2: Raster system

power to prevent a common mode failure due to the loss of ac input voltage. The ac/dc converter charges up and maintains a constant voltage on the capacitor bank. The $\mathrm{dc}$ output voltage of the ac/dc converter is determined by the rastering frequency and the raster magnet inductance $(\mathrm{V}=\mathrm{L} * \mathrm{dI} / \mathrm{dt})$.

The dc capacitor bank exchanges reactive power with the magnet on a $1 \mathrm{kHz}$ time scale (twice per cycle). The IGBT H-bridge controls the transfer of charge back and forth between the capacitor bank and the magnet. The diodes across each switch, referred to as freewheel diodes, recover the stored magnetic energy.

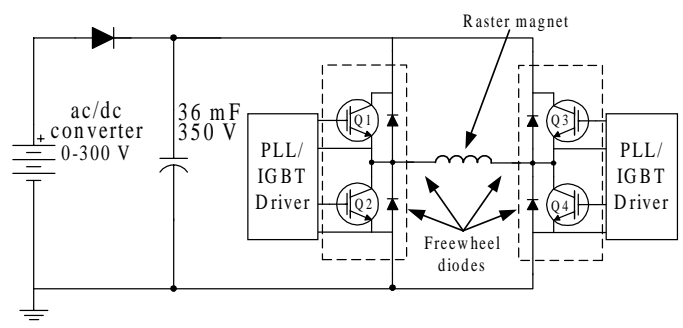

(a)

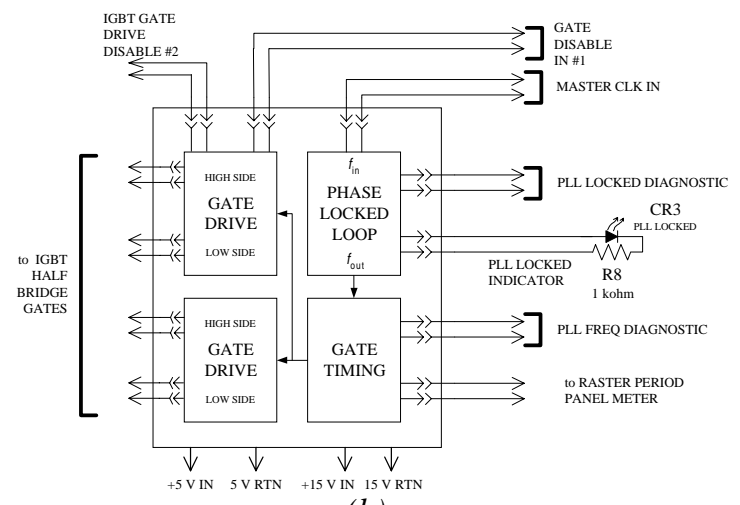

(b)

Figure 3: (a) IGBT modulator schematic and

(b) PLL/IGBT gate drive circuitry. 
The square wave drive voltage of the modulator's $\mathrm{H}$-bridge and the resulting triangular current waveform in the magnet are shown on the next page. Each modulator is rack mounted with its associated ac/dc power supply as shown in Fig. 4. Verification of rms output current and the output frequency are displayed on digital meters on the front panel.

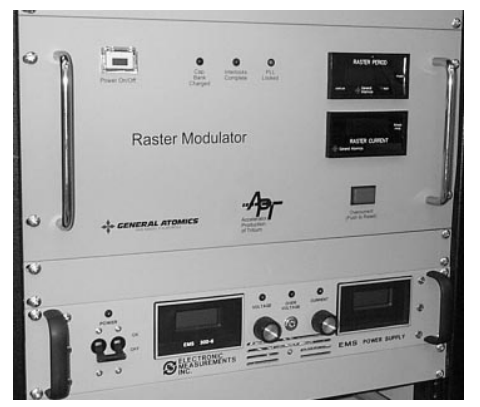

Figure 4: Photo of one modulator and ac/dc converter

Each modulator gets its timing signal from the master clock described in the next section. Each of the modulators has a PLL/IGBT gate driver board that will, using a crystal-controlled phase-locked loop, synchronize itself to the master clock, or else if the master clock fails, is able to produce its own clock so that the beam continues to be rastered onto the target. The phaselock circuit is sequential, rather than an analog type, and the phaselock is accurate to better than $\pm 100 \mathrm{~ns}$. This arrangement is shown in Fig. 3. Such a design approach is used to preclude a common mode failure that might cause damage to the target blanket. The actual hardware consists of a printed circuit card that is mounted inside the modulator enclosure in order to keep the IGBT gate leads as short as possible, and thereby to minimize the drive inductance.

\subsection{Master Clock}

The master clock produces two different frequencies, one for the four $\mathrm{x}$-plane magnets and a second for the four $y$-plane magnets. The frequency reference is a 1.024 $\mathrm{MHz}$ crystal oscillator, identical to those used in each modulator. The choice of $\mathrm{x}$ and $\mathrm{y}$ rastering frequencies, 508.44 and $573.35 \mathrm{~Hz}$ (47/53 ratio) was made to avoid beat patterns and provide uniform beam distribution on the target. The master clock hardware includes on-card fault check circuitry that monitors the clocks to notify the user of a fault. AC power provided to the assembly comes from a UPS, separate from any ac power supplied to the modulators, to preclude a single point failure.

\subsection{Raster Magnet}

The raster magnets are ferrite, $30-\mathrm{cm}$ long with an 8 $\mathrm{cm}$ square aperture. The magnets use Ceramic Magnetics CMD5005 Hi-mu, low loss ferrite. This is a nickel-zinc material with a permeability of $4500 * \mu_{0} \mathrm{H} / \mathrm{m}$ at
1500 Gauss. The magnet has an inductance of $1.4 \mathrm{mH}$ and a field of 620 Gauss at $100 \mathrm{~A}$.

A ceramic (alumina) beam tube is required inside the raster magnets in order to eliminate the eddy currents due to rastering. The ceramic tube has a conducting surface, about one skin depth thick, on the inside to shield the rf field of the $350 \mathrm{MHz}$ proton beam and to conduct the liberated charge from residual gas ionization.

The effect of a metallic layer on the magnetic field was tested with a 1-mil (25-micron) SS304 nonmagnetic stainless steel tube $(2.75$ 'D), with a resistivity of $77 \mu \mathrm{ohm}-\mathrm{cm}$. The tests were performed with a 620 Gauss peak field at $500 \mathrm{~Hz}$. Test results for the power dissipation and the $\mathrm{dB} / \mathrm{dt}$ risetime inside the tube agreed with the following equations for power loss and risetime:

$$
\begin{aligned}
& P=\frac{\pi \ell t a^{3}}{\rho}\left(\frac{d B}{d t}\right)^{2}=24 \text { watts, and } \\
& \tau_{95 \%}=3 \tau=3 \frac{\mu_{0} a t}{2 \rho}=2 \mu \sec (95 \% \text { risetime) },
\end{aligned}
$$

where $l$ is the raster magnet effective length $(35 \mathrm{~cm}), t$ is the foil thickness ( $1 \mathrm{mil}), a$ is the beam tube inside radius (1.375"), dB/dt $=124 \mathrm{~T} / \mathrm{s}$, and $\rho=77 \mu \mathrm{ohm}-\mathrm{cm}$. This verifies that the $\mathrm{rf}$ beam shield will not significantly affect the raster magnet $\mathrm{dB} / \mathrm{dt}$ risetime inside the ceramic tube, and that the eddy current heating can be convectioncooled (does not need active cooling).

\subsection{Fault Detection Circuit}

The beam can not be allowed to stop sweeping across the target. Four independent fault detection circuits, two using $\mathrm{dB} / \mathrm{dt}$ (B-dot) and two using dI/dT (I-dot) sensors on each magnet monitor proper operation of the raster pattern. If a failure is detected, the fault detection circuit removes the beam enable from the Linac, thus shutting down the beam until repairs can be made.

The $16 \mathrm{~B}$-dot and 16 I-dot signals (square waves) are monitored in four completely independent fault detection circuits. Each of these four circuits removes the beam enable signal from one of the four divisions of the fault detection circuitry if it detects a fault. The beam is shut off if two or more of the four beam enable signals are missing.

\section{TEST RESULTS}

The primary raster waveforms as measured in an oscilloscope are shown in Fig. 5. Spikes in the modulator voltage are caused by the unavoidable stray inductances being switched by the IGBTs in the modulator. Because of the freewheeling diodes, the modulator efficiently converts dc input power to reactive magnet power as shown in Fig. 6. As an example, at $500 \mathrm{~Hz}, 32 \mathrm{kVA}$ reactive power requires only $850 \mathrm{~W}$ of real input power (100 A peak, 620 Gauss). Power loss contributions come from the modulator, the cabling, and the raster magnet as follows: 
Eddy currents in magnet coil Resistive loss in magnet coil Voltage drop in IGBTs/diodes Resistive loss in 50-foot cable Other (hysteresis in ferrite, snubber, etc)

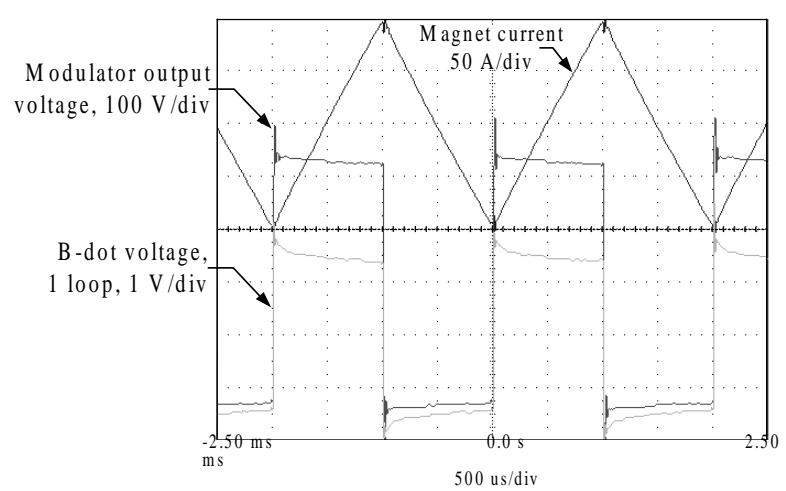

Figure 5: Measured waveform of modulator

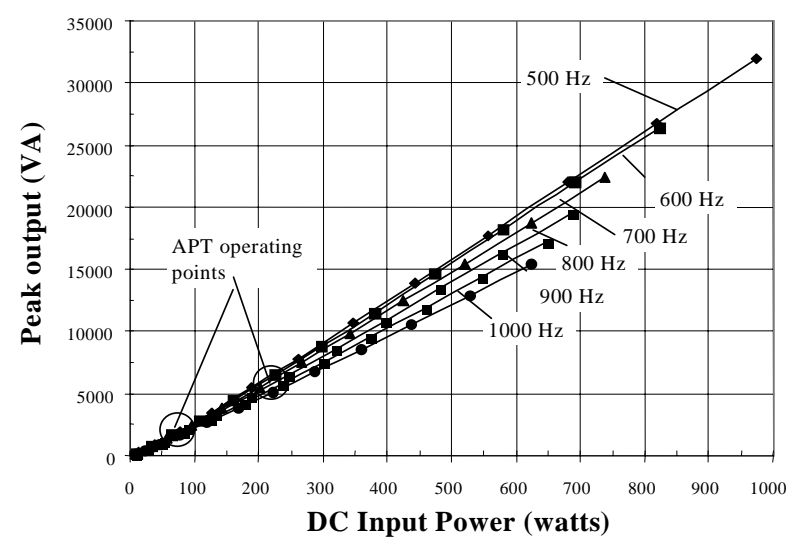

Figure 6: Modulator data of reactive versus real power

As a pair, the magnet and modulator performance test results (Fig. 7) show that the achievable B-field is more than sufficient for the APT requirements of 140-260 G and 500-600 Hz.

Figure 8 shows the $x-y$ raster pattern produced by summing the $\mathrm{x}$ and $\mathrm{y}$ raster magnet current waveforms. There is good agreement between the simulated pattern and the actual measured pattern. The distortion in the pattern is due to the $\mathrm{L} / \mathrm{R}$ droop of the magnets causing a slight curvature in the triangular current waveform. Simulations show that the uniformity of the beam distribution in the $19 \mathrm{~cm}(\mathrm{~h})$ by $190 \mathrm{~cm}(\mathrm{v})$ raster pattern is about $\pm 1 \%$ with a $1-\mathrm{cm}(\mathrm{h})$ by $2-\mathrm{cm}(\mathrm{v}) \mathrm{rms}$ beam spot.

The final tests involve the response of the fault detection circuitry to either a loss of a modulator/magnet unit or the loss of the master clock. When a modulator fails, the summed B-dot pattern reduces in amplitude by $25 \%$ in either $\mathrm{x}$ or $\mathrm{y}$. More interesting is the loss of the master clock, because the square wave slowly evolves into a staircase over many seconds as the voltage controlled crystal oscillators in each modulator drift out of synchronization.

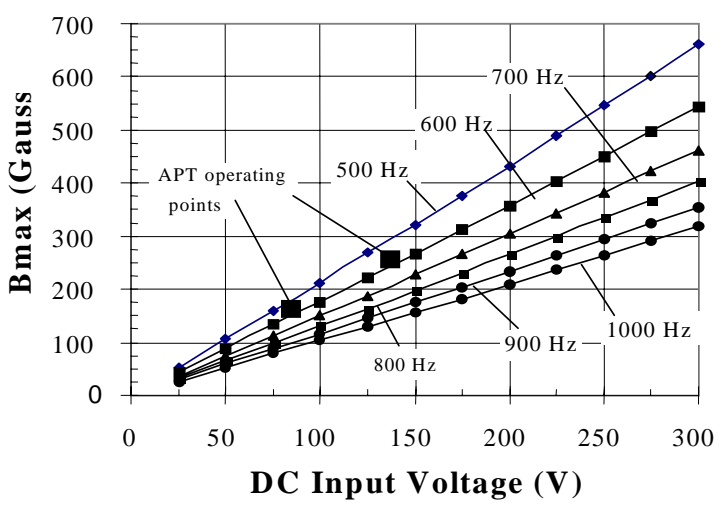

Figure 7: Max B field of magnet vs. modulator dc voltage
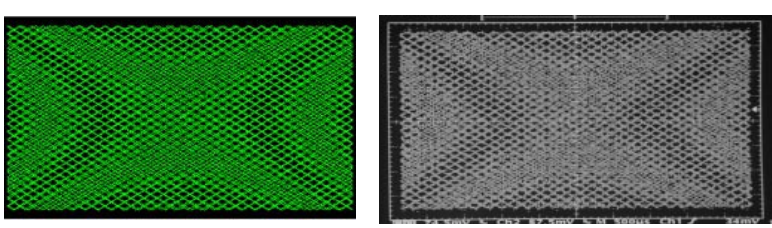

Figure 8: Simulated (1) and real (r) raster patterns

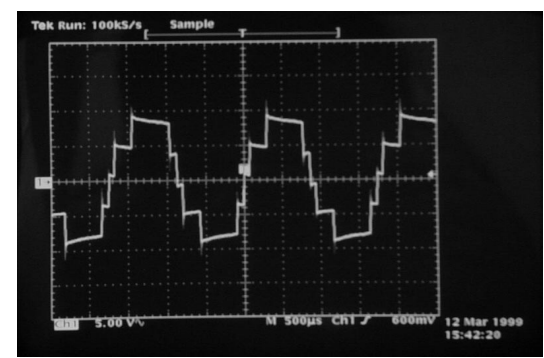

Figure 9: Summed B-dot signal showing loss of PLL synchronization

\section{FUTURE WORK}

System reliability and power consumption can both be improved by replacing the water-cooled hollow copper magnet coil with a stranded Litz wire coil. This will eliminate the water cooling circuits (and interlocks), and substantially reduce the eddy current power loss.

\section{REFERENCES}

[1] C.R. Rose and R.E. Shafer, "A 200-A, 500-Hz, Triangular Current Wave Modulator and Magnet Used for Particle Beam Rastering," Proc. 1997 Particle Accel. Conf., \#7P089 (Vancouver, 5/97).

[2] S. Chapelle, et. al, "Development of a Raster Electronics System for Expanding the APT Proton Beam,” Linac 98 Conference, Aug. 98, Chicago, IL. 